Check for updates

Cite this: RSC Adv., 2018, 8, 7072

Received 2nd January 2018

Accepted 5th February 2018

DOI: $10.1039 / \mathrm{c} 8 \mathrm{ra00016f}$

rsc.li/rsc-advances

\section{Nitrogen-doped hierarchical porous carbon derived from a chitosan/polyethylene glycol blend for high performance supercapacitors}

\begin{abstract}
Yuerong $\mathrm{Ba}^{\mathrm{ab}}$ Wei Pan, ${ }^{\star a b}$ Shangchao $\mathrm{Pi}^{\mathrm{b}}$ Yaomin Zhao ${ }^{\mathrm{a}}$ and Liwei Mi (D) *ab
Nitrogen-doped hierarchical porous carbon (NHPC) materials were synthesized by using a chitosan/ polyethylene glycol (PEG) blend as raw material through a facile carbonization-activation process. In this method, chitosan was used as a nitrogen-containing carbon precursor, low cost and large-scale commercial PEG was employed as a porogen. The physical and electrochemical properties of the resultant NHPC were affected by the ratio of chitosan and PEG. The sample obtained by the ratio of $3: 2$ exhibits a high specific surface area (2269 $\mathrm{m}^{2} \mathrm{~g}^{-1}$ ), moderate nitrogen doping (3.22 at\%) and optimized pore structure. It exhibits a high specific capacitance of $356 \mathrm{~F} \mathrm{~g}^{-1}$ in $1 \mathrm{M} \mathrm{H}_{2} \mathrm{SO}_{4}$ and $271 \mathrm{~F} \mathrm{~g}^{-1}$ in $2 \mathrm{M} \mathrm{KOH}$ at a current density of $1 \mathrm{~A} \mathrm{~g}^{-1}$, and over $230 \mathrm{~F} \mathrm{~g}^{-1}$ can be still retained at a high current density of $20 \mathrm{~A} \mathrm{~g}^{-1}$ in both electrolytes. Additionally, the assembled symmetric supercapacitors show an excellent cycling stability with 94\% (in $1 \mathrm{M} \mathrm{H}_{2} \mathrm{SO}_{4}$ ) and 97\% (in $2 \mathrm{M} \mathrm{KOH}$ ) retention after 10000 cycles at $1 \mathrm{~A} \mathrm{~g}^{-1}$. These results indicate that the chitosan/PEG blend can act as a novel and appropriate precursor to prepare low-cost NHPC materials for high-performance supercapacitors.
\end{abstract}

\section{Introduction}

Supercapacitors, possessing a high power density, superior lifetime, fast charge-discharge ability and excellent safety property, have attracted great attention as next-generation energy storage devices. ${ }^{\mathbf{1 - 6}} \mathrm{A}$ variety of materials have been selected to build high performance supercapacitors to obtain high energy storage capability, such as carbonaceous materials, transition metal oxides and conducting polymers. ${ }^{7-11}$ Of them, carbon materials are thought to be appropriate electrode materials for supercapacitors due to many advantages such as low-cost, easy accessibility and excellent electrical conductivity. ${ }^{12-15}$ However, the relatively low specific capacitance is still hindering their use, ${ }^{\mathbf{1 6}}$ so it is essential to develop carbon electrode materials with high specific capacitance.

In general, improvement of the specific capacitance of carbon materials is usually by introducing heteroatoms (e.g., O, B, N) and regulating pore structure. ${ }^{17-21}$ Structural doping with heteroatoms, especially nitrogen, could improve the capacitance of carbon materials by introducing the pseudo-capacitance. ${ }^{22-24}$ In order to introduce nitrogen, postprocess, for example melamine immersion and ammonia heat treatment, is the most commonly used method..$^{25,26}$ However, these methods may lead to a cumbersome process, pores structure collapse and unstable

${ }^{a}$ School of Materials and Chemical Engineering, Zhongyuan University of Technology, Zhengzhou, 451191, PR China. E-mail: doctorpan0152@163.com

${ }^{b}$ Center for Advanced Materials Research, Zhongyuan University of Technology, Zhengzhou, 451191, PR China.E-mail: mlwzzu@163.com nitrogen functional groups under long-term/harsh working condition. ${ }^{27,28}$ In addition, the subsequently introduced nitrogen functional groups may block up the pores thus reducing the ionaccessible surface area. ${ }^{25,29}$ Although using nitrogen-enriched materials as precursors directly is able to overcome these weaknesses, they also exhibit some defects, such as uncontrollable pore structure and expensive template, ${ }^{\mathbf{3 0 , 3 1}}$ which limits its performance optimization and large-scale applications. Considering these problems, synthesis of NHPC using the lowcost raw materials by a facile approach is very attractive.

Chitosan, the deacetylated derivative of chitin, is the second most popular natural polymer after cellulose. ${ }^{32-34}$ Because of a large number of amino-groups, chitosan can be used to synthesize $\mathrm{N}$-doped carbon materials with excellent supercapacitor performance. ${ }^{33,35}$ However, in contrast to cellulosebased carbons, the research on the preparation of porous carbons using chitosan is still relatively few so far. There are only a few reports about the preparation of $\mathrm{N}$-doped carbons from chitosan, ${ }^{36,37}$ and the pore structure of the obtained carbons is poorly developed, which would greatly hamper their application in supercapacitors. ${ }^{38-40}$ So adding appropriate substances to regulate pore structure is desired. PEG is a water soluble polymer, has good compatibility with chitosan, they can be mixed into homogeneous solutions. ${ }^{41-43}$ During the high temperature carbonization, PEG was removed by thermal degradation, the obtained samples possess ample pore structures, and the pore structure can be regulated by adjusting the ratio of chitosan and PEG. This provides us a good way to 
synthesize NHPC materials for high-performance supercapacitors and there are no other studies have been reported.

Herein, we used chitosan/PEG blend as raw materials to fabricate the NHPC by a facile method. It was found that the porous structure and specific capacitance of NHPC could be adjusted by changing the ratio of chitosan and PEG. The prepared NHPC exhibited an excellent electrochemical performance in both acidic and alkaline medium due to the high specific surface area and hierarchical porous structure.

\section{Experimental}

\section{Preparation of NHPC}

Chitosan and PEG $\left(M_{\mathrm{w}}=6000\right)$ with a total of $5 \mathrm{~g}$ were dissolved in $95 \mathrm{~g}$ acetic acid aqueous solution that was obtained by dissolving $2 \mathrm{~g}$ acetic acid in $93 \mathrm{~g}$ de-ionized water at $50{ }^{\circ} \mathrm{C}$ for $1.5 \mathrm{~h}$ with stirring to obtain a uniform solution. The solution was added onto a glass plate to form a solid film after the evaporation of solvent. Then the as-produced film was peeled off from the glass plate and carbonized at $800{ }^{\circ} \mathrm{C}$ under $\mathrm{N}_{2}$ atmosphere for $2 \mathrm{~h}$ with an increasing rate of $2{ }^{\circ} \mathrm{C} \mathrm{min}^{-1}$. After cooled down to room temperature naturally, the carbonized film was ground into powder. Then the powder was blend with $\mathrm{KOH}$ solution with a power/KOH weight ratio of $1: 3$. The mixture was dried at $110^{\circ} \mathrm{C}$ to evaporate the water. After that, the dried mixture was heated at $800{ }^{\circ} \mathrm{C}$ for $2 \mathrm{~h}$ at $5{ }^{\circ} \mathrm{C} \mathrm{min}^{-1}$ under a $\mathrm{N}_{2}$ atmosphere before being cooled down to room temperature. The product obtained was washed with $1 \mathrm{M} \mathrm{HCl}$ solution and de-ionized water until a neutral $\mathrm{pH}$. Finally, the washed powder was dried at $60{ }^{\circ} \mathrm{C}$ under vacuum overnight to get the NHPC. The sample was signified as the PEG- $x \%$, where $x \%$ stands for the ratio of PEG/(PEG + CS). The synthesis process is schematically presented in Fig. 1.

\section{Characterization}

The morphologies and component of the NHPC materials were characterized by a Zeiss Merlin Compact scanning electron microscope (SEM) equipped with an energy dispersive X-ray spectroscopy (EDX) system. High-resolution transmission electron microscopic (HRTEM) images were obtained with a JEOL JEM2100F microscope. The surface chemical properties of the samples were characterized by X-ray photoelectron spectroscopy (XPS, Escalab 250, USA). X-ray diffraction (XRD) patterns were conducted using a X-ray powder diffractometer (Bruker D8 Advance) with $\mathrm{Cu}-\mathrm{K} \alpha$ irradiation. Raman spectra were acquired with a Raman spectrometer (LabRAM HR Evolution). Thermogravimetry (TG) was carried out on a TG209F1 under nitrogen flow. $\mathrm{N}_{2}$ adsorption-desorption isotherms were measured at $77 \mathrm{~K}$ using ASAP $2420 \mathrm{~V} 2.09 \mathrm{~A}$. The specific surface area was measured using the Brunauer-Emmett-Teller (BET) method and the pore size distribution (PSD) was determined using the classical Barrett-Joyner-Halenda (BJH) model.

\section{Electrochemical measurements}

Working electrodes were prepared by pressing a disk $(1 \mathrm{~cm}$ diameter) containing $80 \mathrm{wt} \%$ of active material, $10 \mathrm{wt} \%$ of acetylene black and $10 \mathrm{wt} \%$ of polytetrafluoroethylene onto nickel foam (used in $\mathrm{KOH}$ solution) and stainless steel mesh (used in $\mathrm{H}_{2} \mathrm{SO}_{4}$ solution). The active mass was 2.0-3.0 $\mathrm{mg}$ per electrode. The electrochemical performances of as-prepared electrodes were studied in $1 \mathrm{M} \mathrm{H}_{2} \mathrm{SO}_{4}$ and $2 \mathrm{M} \mathrm{KOH}$ solution using a three-electrode and two-electrode system on a CHI660E electrochemical workstation (Chenhua Instruments Co. Ltd., Shanghai). In the three-electrode system, platinum foil and Ag/ $\mathrm{AgCl}$ electrode were used as the counter and reference electrodes, respectively. Cyclic voltammetry (CV), galvanostatic charge-discharge (GCD) and Electrical Impedance Spectroscopy (EIS) measurements were performed. The specific capacitance $\left(C_{\mathrm{g}}\right)$ can be calculated by using the formula of $C_{\mathrm{s}}=I \times \Delta t /(m \times$ $\Delta V$ ), where $I$ is the discharge current (A), $\Delta t$ is the discharge time (s), $m$ is the mass ( $\mathrm{g}$ ) of the active materials, and $\Delta V$ is the potential window (V) during discharge. ${ }^{\mathbf{4 4 , 4 5}}$ The specific capacitance of the two-electrode symmetrical supercapacitor cell can

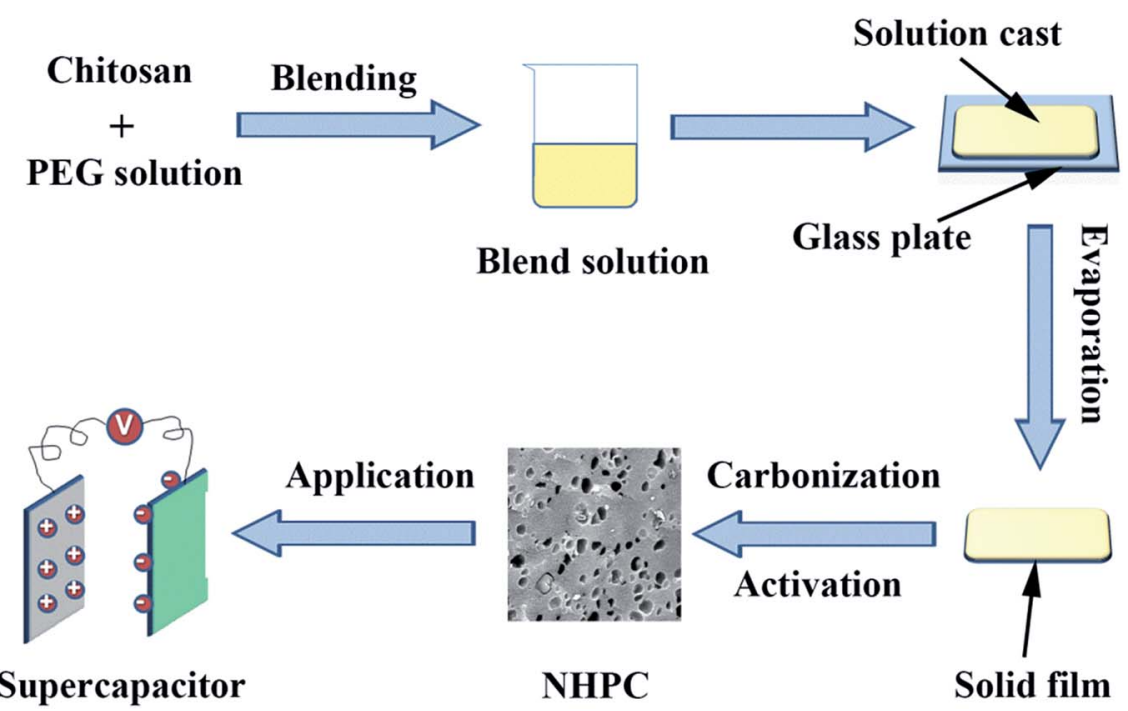

Fig. 1 Schematic illustration of the preparation of NHPC materials. 
be calculated by using the formula of $C_{\text {cell }}=I \times \Delta t /(M \times \Delta V)$, where $C_{\text {cell }}$ is the total cell specific capacitance $\left(\mathrm{F} \mathrm{g}^{-1}\right)$, and $M$ is the total mass $(\mathrm{g})$ of active materials in both electrode. The energy and power densities $\left(E, \mathrm{~W} \mathrm{~h} \mathrm{~kg}{ }^{-1}\right.$ and $\left.P, \mathrm{~W} \mathrm{~kg}^{-1}\right)$ were calculated according to the equation of $E=1 / 2 C_{\text {cell }} V^{2}$ and $P=E /$ $t$, in which $C_{\text {cell }}$ is the specific capacitance of the device, $V$ is the voltage decrease in discharge, and $t$ is the discharge time. The long-term cycling performance of electrodes were measured by a symmetrical supercapacitor in $1 \mathrm{M} \mathrm{H}_{2} \mathrm{SO}_{4}$ and $2 \mathrm{M} \mathrm{KOH}$ solution at a current density of $1 \mathrm{~A} \mathrm{~g}^{-1}$ on a Land Battery Tester (LAND electronics Co. Ltd, Wuhan) at ambient temperature.

\section{Results and discussion}

\section{Characterization of the prepared materials}

Fig. $2 \mathrm{a}-\mathrm{f}$ show the SEM images of the NHPC materials. It can be seen that all samples possess pore structures, and such a porous structure renders the electrolyte able to penetrate into the bulk particles to form three-dimensional channels for ions' transportation. It is obviously observed that the microstructure and morphology are seriously affected by the PEG content. With the increase of PEG in the preparation process, the pores of samples are increase. In contrast, PEG-50\% has the 3D network structure with plentiful and loose pores randomly. Fig. $2 \mathrm{~g}$ shows the HRTEM images of PEG-40\% samples. It can be seen that PEG$40 \%$ mainly exhibits an amorphous structure, and some locally ordered structure could be observed, as marked by the red arrows, indicating partial graphitization of the synthesized materials.

The element composition of the PEG-40\% sample was determined by XPS measurement (Fig. 3). The strong signals in the survey XPS spectra reveal the existence of three peaks at 284.8, 400.9 and $532.6 \mathrm{eV}$, corresponding to $\mathrm{C} 1 \mathrm{~s}, \mathrm{~N} 1 \mathrm{~s}$ and $\mathrm{O} 1 \mathrm{~s}$, respectively (Fig. 3a). High resolution XPS measurements were performed to investigate the atom binding states. In case of $\mathrm{C}$ $1 \mathrm{~s}$, four peaks at $284.8,285.4,286.4$ and $288.8 \mathrm{eV}$ corresponding to $\mathrm{Csp}^{2}, \mathrm{C}-\mathrm{O} / \mathrm{C}-\mathrm{N}, \mathrm{C}=\mathrm{O}$ and $\mathrm{O}-\mathrm{C}=\mathrm{O}$ groups was observed. The $\mathrm{N} 1 \mathrm{~s}$ was determined by $398.5,400.3$ and $401.2 \mathrm{eV}$, which can be attributed to pyridinic N, pyrrolic $\mathrm{N}$ and graphitic N, respectively. ${ }^{45} \mathrm{In}$ case of $\mathrm{O} 1 \mathrm{~s}$, three peaks at 531.8, 532.7, and $533.6 \mathrm{eV}$, corresponding to $\mathrm{C}=\mathrm{O}$ (carbonyl), $\mathrm{C}-\mathrm{O}$ (epoxy and
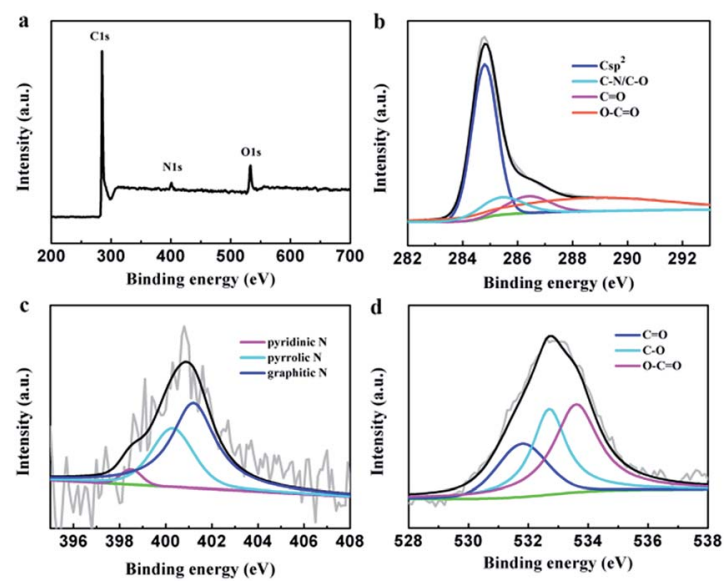

Fig. 3

(a) XPS survey, (b) C 1s, (c) N 1s, and (d) $O 1$ s of PEG-40\%.

hydroxyl), and $\mathrm{O}=\mathrm{C}-\mathrm{O}$ (carboxyl) groups are determined. The XPS results demonstrated the effective doping of nitrogen by chitosan in the preparation process.

The as-prepared carbon materials were further analyzed by XRD and Raman patterns to confirm the graphitized structure. All XRD patterns in Fig. 4a show the diffraction peaks at $2 \theta$ around $25^{\circ}$ and $43^{\circ}$, corresponding to (002) and (100) crystallographic planes, respectively. From the picture it can be seen that PEG-50\% had a low order degree, which is in good agreement with SEM analysis (Fig. 2). Fig. 4b presents the Raman patterns of PEG-30\%, PEG-40\% and PEG-50\% samples. All three samples display $\mathrm{G}$ (around $1580 \mathrm{~cm}^{-1}$ ) and $\mathrm{D}$ (around $1340 \mathrm{~cm}^{-1}$ ) bands, reflection of ordered and disordered structures, ${ }^{23}$ respectively. And the narrower G-band and the lower intensity of $I_{\mathrm{D}} / I_{\mathrm{G}}$ often imply higher ordered structures and graphitizatio degree. ${ }^{24,32,45}$ The values of $I_{\mathrm{D}} / I_{\mathrm{G}}$ for PEG-30\%, PEG$40 \%$ and PEG-50\% were $0.93,0.94$ and 1.07 , respectively, this result demonstrates that the degree of graphitization decreases with the PEG content increases, and PEG-50\% sample possesses much lower degree of graphitization than others, which is identical with the results of above XRD analysis.

The thermal decomposition curves of PEG- $0 \%$ to PEG-50\% solid films and pure PEG were shown in Fig. 4c. The pure PEG
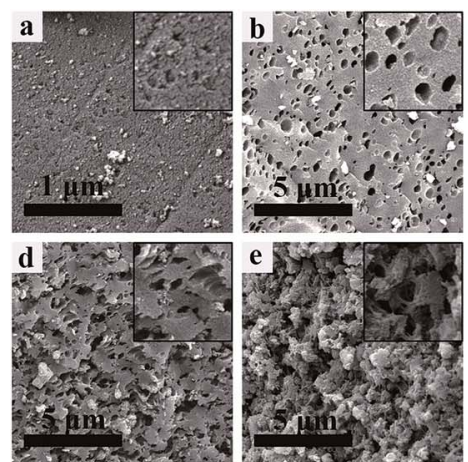
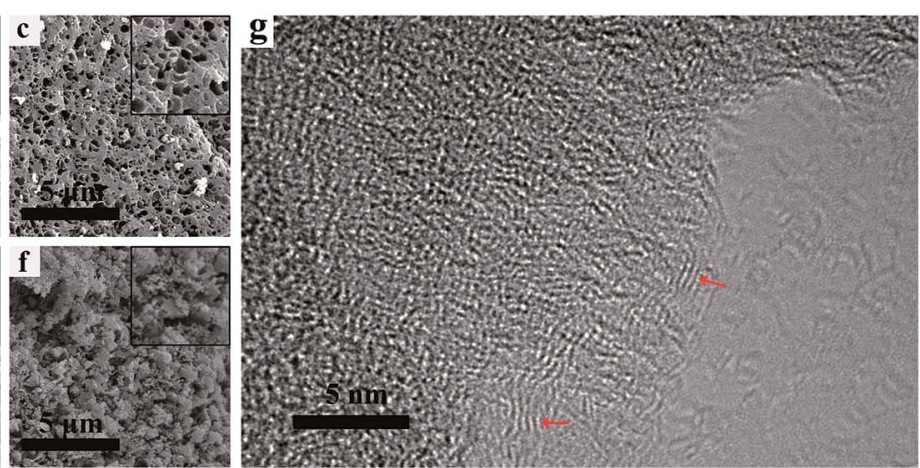

Fig. 2 SEM images of (a) PEG-0\%, (b) PEG-10\%, (c) PEG-20\%, (d) PEG-30\%, (e) PEG-40\%, (f) PEG-50\% and (g) HRTEM image of the PEG-40\% sample. 

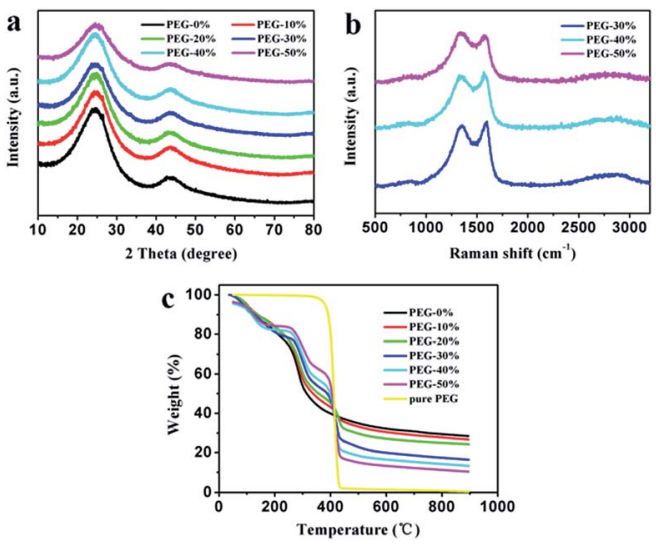

Fig. 4 XRD patterns (a) and Raman spectra (b) of the carbon materials Thermal decomposition curves (c) of different solid films.

exhibited only one stage around $360-440{ }^{\circ} \mathrm{C}$ due to the thermal degradation of PEG. When the temperature reaches to $800{ }^{\circ} \mathrm{C}$, the weight loss of PEG was $99.2 \%$, indicating that PEG was almost complete decomposition. The PEG-0\% exhibited two stages around $80-150{ }^{\circ} \mathrm{C}$ and $250-350^{\circ} \mathrm{C}$ due to the evaporation of water and thermal degradation of chitosan, respectively. The other samples showed three distinct stages from 30 to $900{ }^{\circ} \mathrm{C}$, which were attributed to the evaporation of water (around 80$150{ }^{\circ} \mathrm{C}$ ), thermal degradation of chitosan (around $250-350{ }^{\circ} \mathrm{C}$ ), and thermal degradation of PEG (around $360-440^{\circ} \mathrm{C}$ ). It can be seen that carbon residue increases during following the increasement of chitosan, which is in good agreement with above analysis.

$\mathrm{N}_{2}$ adsorption-desorption isotherms were performed to examine the specific surface area and the pore size and distribution in the samples. As shown in Fig. 5a, all isotherms exhibit type IV with uptake at low pressure and small hysteresis loops ranging from 0.5 to 1.0 , which imply the coexistence of micropores, mesopores, and macropores in these samples. ${ }^{8}$ This
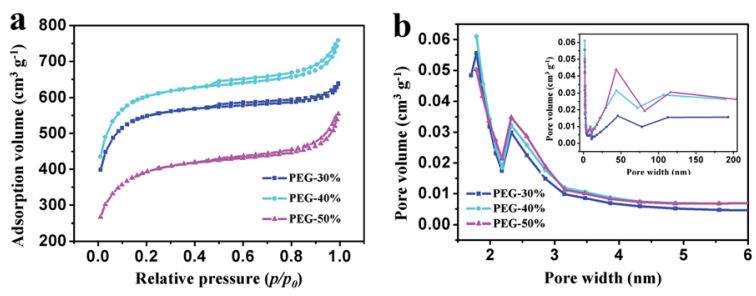

Fig. 5 (a) $\mathrm{N}_{2}$ adsorption-desorption isotherms at $77 \mathrm{~K}$ and (b) PSD curves of PEG-30\%, PEG-40\% and PEG-50\% samples. result can be further confirmed by using BJH model to calculate the pore size distribution. And the hierarchical porous structure is conform to the ideal supercapacitor electrode materials that containing macropores, mesopores and micropores for ion buffering reservoir, ion transport and enhancement of charge storage, ${ }^{33}$ respectively. The data on specific surface area and pore volume are listed in Table 1. With the increase of PEG content, the total pore volume was increase, moreover, the mesopores and macropores volume was increase and the micropores volume was decrease. Compared with PEG-40\%, the total pore volume of PEG-50\% has a slight increase due to the high content of PEG. When the content of PEG is too high, a large number of PEG gather together and leave large pores after decomposition, and large pore size may lead to pores structure collapse seriously in the process of post treatment and more pore volume was destroyed when grinding into powder. With the increase of PEG content, the specific surface area increased firstly and then decreased, this is the results of combined action of pore volume and pore size. With the increase of PEG content, the pore volume was increase, although the pore size would also increase, the pore volume increased substantially, so the specific surface area will increase. The pore volume increased little when the PEG content reaches a certain value, the effect less than the pore size, therefore the specific surface area decreased rapidly with the increase of PEG content. From the above results, it can be seen that different proportion can influence the specific surface area and pore volume. Sample PEG- $40 \%$ has the most suitable pore size and size distribution, which is expected to enhance its behavior as a capacitor.

\section{Electrochemical performance}

Electrochemical properties of the resultant NHPC materials were measured using a standard three-electrode configuration in both acidic and alkaline solution. Fig. 6a and 7a show the typical CV curves of samples at a scan rate of $10 \mathrm{mV} \mathrm{s}^{-1}$ in $1 \mathrm{M}$ $\mathrm{H}_{2} \mathrm{SO}_{4}$ and $2 \mathrm{M} \mathrm{KOH}$, respectively. In both cases, the covered area of PEG- $40 \%$ sample is larger than the other samples, it illustrates that PEG- $40 \%$ sample possesses the highest capacitance, which was consistent with the physical characteristics. And all the samples present a rectangular-like shape with obvious redox peaks due to the introduction of $\mathrm{N}$ heteroatom in carbon materials. The pseudocapacitance in acidic electrolyte is more obvious than that in basic electrolyte, probably owing to the Lewis base behavior of the nitrogen functionalities in the carbons. ${ }^{44}$ In order to further investigate the capacitance behavior of PEG- $40 \%$ material, the CV curves at different

Table 1 Porous property of PEG-30\%, PEG-40\% and PEG-50\% samples

\begin{tabular}{lllllrr}
\hline Sample & $S_{\text {BET }}\left(\mathrm{m}^{2} \mathrm{~g}^{-1}\right)$ & $V_{\text {total }}\left(\mathrm{cm}^{3} \mathrm{~g}^{-1}\right)$ & $V_{\text {micro }}$ & $V_{\text {meso }}$ & $V_{\text {macro }}$ & Pore size (nm) \\
\hline PEG-30\% & 2052 & 0.429 & 0.146 & 0.226 & 0.057 \\
PEG-40\% & 2269 & 0.516 & 0.107 & 0.302 & 0.107 & 2.7 \\
PEG-50\% & 1436 & 0.520 & 0.091 & 0.309 & 0.120 & 3.5
\end{tabular}



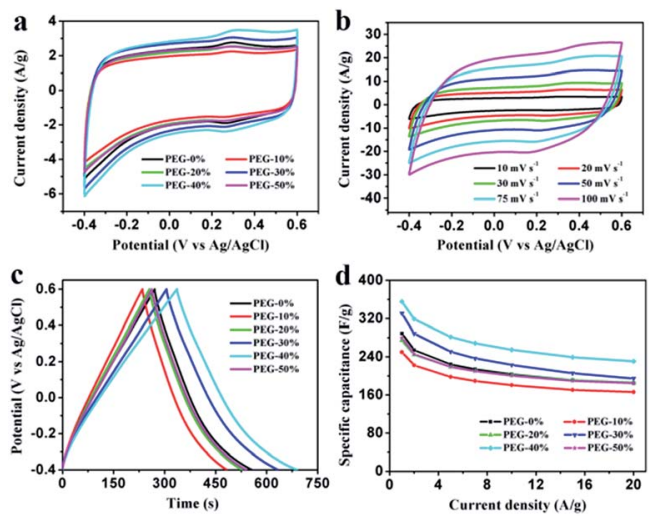

Fig. 6 Electrochemical performances of the PEG- $x \%$ materials based electrode measure in a three-electrode system in $1 \mathrm{M} \mathrm{H}_{2} \mathrm{SO}_{4}$ aqueous electrolyte. (a) CV curves at a scan rate of $10 \mathrm{mV} \mathrm{s}^{-1}$; (b) CV curves of PEG-40\% electrode material at different scan rates; (c) GCD curves at a current density of $1 \mathrm{~A} \mathrm{~g}^{-1}$; (d) specific capacitances at different current densities.
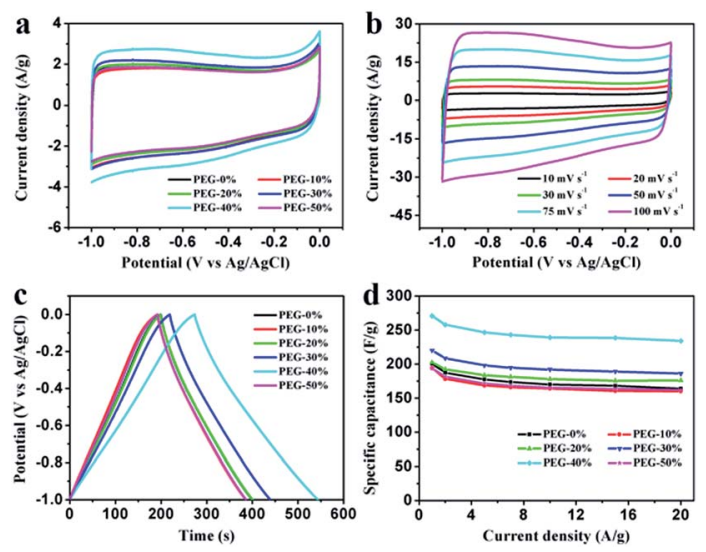

Fig. 7 Electrochemical performances of the PEG- $x \%$ materials based electrode measure in a three-electrode system in $2 \mathrm{M} \mathrm{KOH}$ aqueous electrolyte. (a) CV curves at a scan rate of $10 \mathrm{mV} \mathrm{s}^{-1}$; (b) CV curves of PEG-40\% electrode material at different scan rates; (c) GCD curves at a current density of $1 \mathrm{~A} \mathrm{~g}^{-1}$; (d) specific capacitances at different current densities.

scanning rates were measured. The shapes of CV curves can be well retained even under the high scan rate (Fig. $6 \mathrm{~b}$ and $7 \mathrm{~b}$ ), indicating a superb capacitive behavior.
Fig. $6 \mathrm{c}$ and $7 \mathrm{c}$ show the GCD curves of each sample at the current density of $1 \mathrm{~A} \mathrm{~g}^{-1}$. The curves show a typical triangular shape with slight curvature, and the deviation from linearity is due to the pseudo faradic reactions during the charging-discharging process, which is consistent with the CV curves. Compared with other samples, PEG- $40 \%$ has the much larger capacitance owing to its high specific surface area $\left(2269 \mathrm{~m}^{2} \mathrm{~g}^{-1}\right)$ and moderate N-doped (3.22\% obtained by EDX). Its $C_{\mathrm{s}}$ is as high as 356 and $271 \mathrm{~F} \mathrm{~g}^{-1}$ in $1 \mathrm{M} \mathrm{H}_{2} \mathrm{SO}_{4}$ and $2 \mathrm{M} \mathrm{KOH}$, respectively. Fig. $6 \mathrm{~d}$ and $7 \mathrm{~d}$ show the capacitance retention for current density from 1 to $20 \mathrm{~A} \mathrm{~g}^{-1}$, the specific capacitances progressively decrease with the increase of current density due to the increasing diffusion limitation. However, PEG-40\% can still retain over $230 \mathrm{~F} \mathrm{~g}^{-1}$ at a high current density of $20 \mathrm{~A} \mathrm{~g}^{-1}$ in both electrolytes, which means a good rate performance for the supercapacitor. The performances of different $\mathrm{N}$-doped porous carbons are listed in Table 2. Overall, the performance of the asprepared carbon materials in this work is superior to those proposed in the literature.

Fig. 8 shows the Nyquist plot of the samples at the frequency range from $0.01 \mathrm{~Hz}$ to $100 \mathrm{kHz}$ to further investigate the capacitive property of the electrodes. The Nyquist plots were measured in a three-electrode system at the open circuit voltage. And the plot of PEG- $40 \%$ is modeled and interpreted with the assistant of an appropriate electric equivalent circuit. The Nyquist plot could be divided to three parts, including an uncompleted semicircle part at high frequency, an inclined portion about $45^{\circ}$ at the middle frequency and a linear part at low frequency. The high-frequency intercept with the real axis of PEG- $40 \%$ gives the resistance value $\left(R_{\mathrm{S}}\right)$ of $1.6 \Omega$ (in $1 \mathrm{M} \mathrm{H}_{2} \mathrm{SO}_{4}$ ) and $0.29 \Omega$ (in $2 \mathrm{M} \mathrm{KOH}$ ) which includes the electrolyte
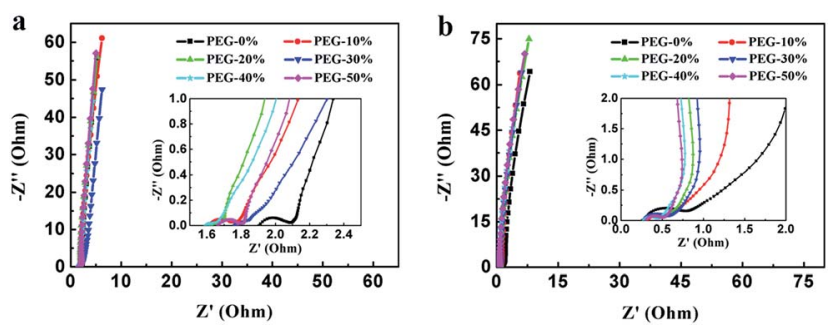

Fig. 8 Nyquist plots measured in $1 \mathrm{M} \mathrm{H}_{2} \mathrm{SO}_{4}$ (a) and $2 \mathrm{M} \mathrm{KOH}$ (b). The inset shows a magnified view of the high frequency region of the impedance spectra.

Table 2 Comparison of performances of different $\mathrm{N}$-doped porous carbons

\begin{tabular}{|c|c|c|c|c|}
\hline Materials & $S_{\mathrm{BET}}\left(\mathrm{m}^{2} \mathrm{~g}^{-1}\right)$ & $C_{\mathrm{g}}\left(\mathrm{F} \mathrm{g}^{-1}\right)$ & Cycle performance & Reference \\
\hline K800 & 2435 & $197\left(0.2 \mathrm{~A} \mathrm{~g}^{-1}\right)$ & $92 \%$ after 10000 cycles at $1 \mathrm{~A} \mathrm{~g}^{-1}$ & 6 \\
\hline $\mathrm{RGH}_{3}-1$ & 173 & $258\left(0.1 \mathrm{~A} \mathrm{~g}^{-1}\right)$ & $97 \%$ after 4000 cycles at $1 \mathrm{~A} \mathrm{~g}^{-1}$ & 16 \\
\hline NCNF3 & 763 & $251\left(0.1 \mathrm{~A} \mathrm{~g}^{-1}\right)$ & $99 \%$ after 2000 cycles at $5 \mathrm{~A} \mathrm{~g}^{-1}$ & 25 \\
\hline NHPC-800 & 1542 & $242\left(0.2 \mathrm{~A} \mathrm{~g}^{-1}\right)$ & $94 \%$ after 10000 cycles at $1 \mathrm{~A} \mathrm{~g}^{-1}$ & 32 \\
\hline 3DHCG & 1511 & $320\left(1 \mathrm{~A} \mathrm{~g}^{-1}\right)$ & $96 \%$ after 2000 cycles at $2 \mathrm{~A} \mathrm{~g}^{-1}$ & 45 \\
\hline
\end{tabular}


resistance, the active material resistance, and the active material interface resistance. The lower value of $R_{\mathrm{s}}$ is associated with better electrode conductivity. The diameter of the semi-circle is a charge-transfer resistance $\left(R_{\mathrm{ct}}\right)$, which is attributed to the charge transfer at the interface of the electrode and electrolyte, and a smaller semicircle means smaller charge transfer resistance. The $R_{\mathrm{ct}}$ of PEG-40\% electrode is $0.03 \Omega$ (in $1 \mathrm{M} \mathrm{H}_{2} \mathrm{SO}_{4}$ ) and $0.13 \Omega$ (in $2 \mathrm{M} \mathrm{KOH}$ ), which is lower than those of other electrode materials. The $45^{\circ}$ slope region at middle frequency can be attributed to the ions diffusion/transport from the electrolyte to the pore on the surface of samples. The short lengths of these slopes indicate that the electrolyte ions diffuse fast in this carbon framework. The almost vertical line represents the dominance of ideal double-layer charge/discharge behaviors at low frequencies.

To further study the electrochemical behavior of the PEG$40 \%$ electrode as a real capacitor in $1 \mathrm{M} \mathrm{H}_{2} \mathrm{SO}_{4}$ and $2 \mathrm{M} \mathrm{KOH}$ solution, a symmetrical two-electrode configuration was constructed. It can be observed that the fabricated symmetric supercapacitor shows near-rectangular shapes in both acid and basic solution (Fig. 9a and b), even at high scan rates, indicating its ideal capacitive behavior. ${ }^{45}$ Moreover, the GCD curves in Fig. $9 \mathrm{c}$ and $d$ display good symmetrical linear curves, revealing its high electrochemical stability. The specific capacitance of the symmetric supercapacitors calculated from GCD curves is $55 \mathrm{~F} \mathrm{~g}^{-1}$ and $42 \mathrm{~F} \mathrm{~g}^{-1}\left(220 \mathrm{~F} \mathrm{~g}^{-1}\right.$ and $168 \mathrm{~F} \mathrm{~g}^{-1}$ for single electrode) at $0.5 \mathrm{~A} \mathrm{~g}^{-1}, 91 \%$ and $86 \%$ capacitance is retained even at $5 \mathrm{~A} \mathrm{~g}^{-1}$ in $1 \mathrm{M} \mathrm{H}_{2} \mathrm{SO}_{4}$ and $2 \mathrm{M} \mathrm{KOH}$, respectively. Stability testing was conducted under $1 \mathrm{~A} \mathrm{~g}^{-1}$ for 10000 cycles. Fig. 9e and $\mathrm{f}$
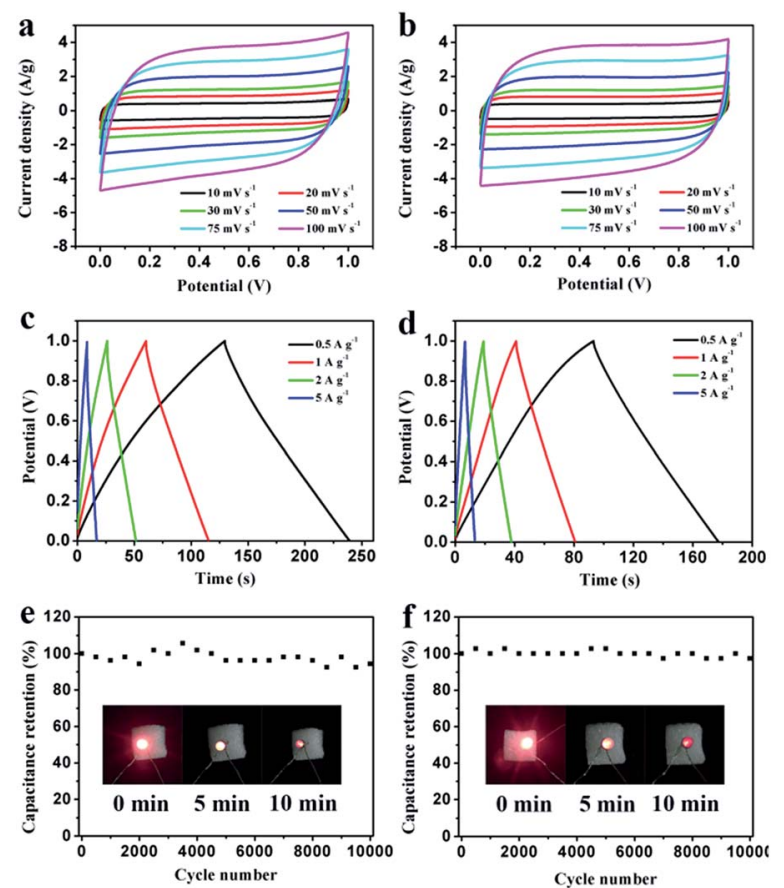

Fig. 9 Electrochemical performance of PEG-40\% symmetrical supercapacitors in $1 \mathrm{M} \mathrm{H}_{2} \mathrm{SO}_{4}$ and $2 \mathrm{M} \mathrm{KOH}$, respectively. $(a, b) \mathrm{CV}$ curves at different scanning rates; (c, d) GCD curves at different current densities; (e, f) cycling stability at a $1 \mathrm{~A} \mathrm{~g}^{-1}$.

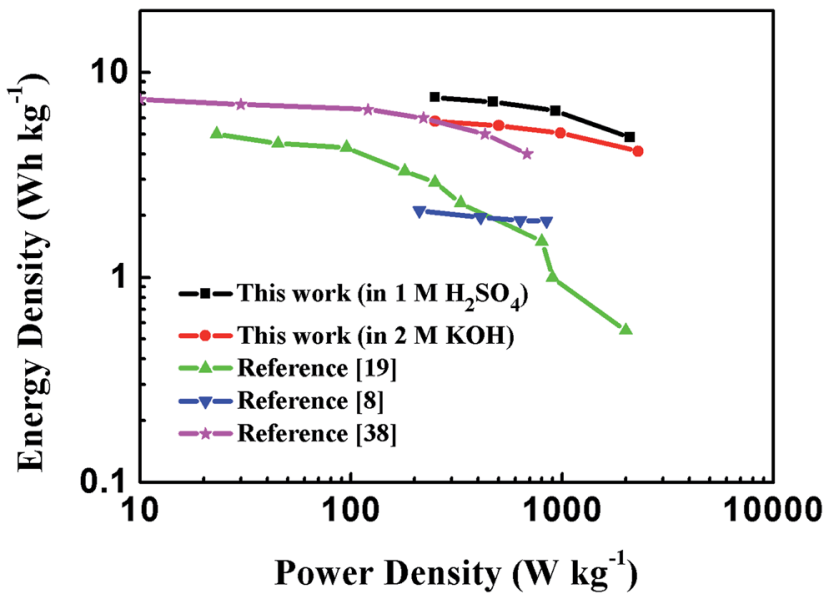

Fig. 10 Ragone plot comparing the energy density and power density of PEG-40\% symmetric supercapacitor with other reported carbon materials in an aqueous electrolyte.

show the cycling stability of the symmetric supercapacitors in $1 \mathrm{M} \mathrm{H}_{2} \mathrm{SO}_{4}$ and $2 \mathrm{M} \mathrm{KOH}$, respectively. The capacitance retention is about $94 \%$ and $97 \%$ of its initial value after 10000 cycles, indicating the excellent cycling stability of PEG- $40 \%$. To further demonstrate the device performance after cycles, two supercapacitors were connected in series to light a red LED. As shown in Fig. 9e and $\mathrm{f}$, after charging to $2.2 \mathrm{~V}$ at a current density of $1 \mathrm{~A} \mathrm{~g}^{-1}$, the device could power a red LED, and even after $10 \mathrm{~min}$ the red LED still remained bright, indicating its excellent electrochemical properties even after 10000 cycles.

Energy and power densities are key parameters to evaluate the performance of a certain material when applied as electrodes for supercapacitors. The Ragone plot of PEG- $40 \%$ symmetric supercapacitor in $1 \mathrm{M} \mathrm{H}_{2} \mathrm{SO}_{4}$ and $2 \mathrm{M} \mathrm{KOH}$ aqueous solutions calculated from discharge curves at different current densities is displayed in Fig. 10, as well as its comparison with the representative porous carbon-based supercapacitors. The results showed that the energy density of the supercapacitors utilizing PEG-40\% as electrode material could reach $7.58 \mathrm{~W} \mathrm{~h} \mathrm{~kg}^{-1}$ with a corresponding specific power density of $0.25 \mathrm{~kW} \mathrm{~kg}^{-1}$ in $1 \mathrm{M} \mathrm{H}_{2} \mathrm{SO}_{4}$ solution, and an energy density of $5.79 \mathrm{~W} \mathrm{~h} \mathrm{~kg}^{-1}$ could be obtained with $0.25 \mathrm{~kW} \mathrm{~kg}^{-1}$ of specific power in $2 \mathrm{M} \mathrm{KOH}$ electrolyte, which is higher than those of commercially available supercapacitors $\left(3-5 \mathrm{~W} \mathrm{~h} \mathrm{~kg}^{-1}\right)^{24}$ and most carbon-based/N-doped carbonaceous aqueous capacitors reported in previous articles.

\section{Conclusions}

In summary, NHPC materials have been fabricated by the carbonization of chitosan/PEG blend and activation with KOH. Benefiting from its hierarchical porous structure and numerous pseudocapacitive functional groups, the carbon materials exhibits an excellent performance. As an example, the PEG- $40 \%$ sample has micro, meso-, and macro- hierarchical porous structure and possesses a high specific surface area of $2269 \mathrm{~m}^{2} \mathrm{~g}^{-1}$. It can deliver high specific capacitances of $356 \mathrm{~F} \mathrm{~g}^{-1}$ (in $1 \mathrm{M} \mathrm{H}_{2} \mathrm{SO}_{4}$ ) 
and $271 \mathrm{~F} \mathrm{~g}^{-1}$ (in $2 \mathrm{M} \mathrm{KOH}$ ) at the current density of $1 \mathrm{~A} \mathrm{~g}^{-1}$, retain $65 \%$ and $86 \%$ at $20 \mathrm{~A} \mathrm{~g}^{-1}$. Furthermore, the assembled symmetric supercapacitors show an excellent cycling stability with $94 \%$ (in $1 \mathrm{M} \mathrm{H}_{2} \mathrm{SO}_{4}$ ) and $97 \%$ (in $2 \mathrm{M} \mathrm{KOH}$ ) retention after 10000 cycles at $1 \mathrm{~A} \mathrm{~g}^{-1}$. The outstanding capacitive behavior is attributed to the unique features including a high specific surface area, reasonable pore size and pore size distribution, and moderate nitrogen doping. These demonstrated that using low-cost biopolymer as the raw material to produce NHPC materials is a promising approach for the development of energy storage systems.

\section{Conflicts of interest}

There are no conflicts to declare.

\section{Acknowledgements}

This work is supported by the National Natural Science Foundation of China (Grant No. 21671205 and U1407103), Collaborative Innovation Centre of Henan Textile and Clothing Industry, Innovation Scientists and Technicians Troop Construction Projects of Henan Province (Grant No. 164100510007 and CXTD2015018) and the Open cooperation project of Henan Province (152106000057).

\section{References}

1 X. Xu, J. Tang, H. Qian, S. Hou, Y. Bando, M. S. A. Hossain, L. Pan and Y. Yamauchi, ACS Appl. Mater. Interfaces, 2017, 9, 38737-38744.

2 J. Yang, Y. Yuan, W. Wang, H. Tang, Z. Ye and J. Lu, J. Power Sources, 2017, 340, 6-13.

3 Y. Gao, L. Wang, W. Zhang, X. Yang, Y. Ma, J. Shao and Y. Li, Electrochim. Acta, 2016, 201, 260-267.

4 B. D. Boruah and A. Misra, ACS Energy Lett., 2017, 2, 17201728.

5 P. Hu, T. Chen, Y. Yang, H. Wang, Z. Luo, J. Yang, H. Fu and L. Guo, Nanoscale, 2017, 9, 1423.

6 L. Guo, X. Wang and Y. Wang, Chem. Eng. J., 2017, 313, 12951301.

7 B. D. Boruah and A. Misra, Energy Storage Materials, 2016, 5, 103-110.

8 D. Schopf and M. Es-Souni, Appl. Phys. A: Mater. Sci. Process., 2016, 122, 203.

9 B. D. Boruah and A. Misra, J. Mater. Chem. A, 2016, 4, 1755217559.

$10 \mathrm{X} . \mathrm{Wu}$, V. L. Chabot, B. K. Kim, A. Yu, R. M. Berry and K. C. Tom, ACS Energy Lett., 2014, 138, 139-147.

11 B. D. Boruah, A. Maji and A. Misra, Nanoscale, 2017, 9, 94119420.

12 Y. Wang, Y. Liu, W. Liu, G. Zhang, G. Liu, H. Chen and J. Yang, J. Alloys Compd., 2016, 677, 105-111.

13 K. Sun, S. Yu, Z. Hu, Z. Li, G. Lei, Q. Xiao and Y. Ding, Electrochimica. Acta, 2017, 231, 417-428.

14 F. Sun, J. Gao, X. Pi, L. Wang, Y. Yang, Z. Qu and S. Wu, J. Power Sources, 2017, 337, 189-196.
15 L. Zhu, F. Shen, R. L. Smith Jr, L. Yan, L. Li and X. Qi, Chem. Eng. J., 2017, 316, 770-777.

16 X. Tian, N. Zhao, Y. Song, K. Wang, D. Xu, X. Li, Q. Guo and L. Liu, Electrochim. Acta, 2015, 185, 40-51.

17 J. Zeng, Q. Cao, X. Wang, B. Jing, X. Peng and X. Tang, J. Solid State Electrochem., 2015, 19, 1591-1597.

18 A. Sanchez-Sanchez, M. T. Izquierdo, J. Ghanbaja, G. Medjahdi, S. Mathieu, A. Celzard and V. Fierro, J. Power Sources, 2017, 344, 15-24.

19 A. Elmouwahidi, E. Bailón-García, A. F. Pérez-Cadenas, F. J. Maldonado-Hódar and F. Carrasco-Marín, Electrochim. Acta, 2017, 229, 219-228.

20 Z. Y. Li, M. S. Akhtar, D. Kwak and O. Yang, Appl. Surf. Sci., 2017, 404, 88-93.

21 N. Phattharasupakun, J. Wutthiprom, P. Suktha, P. Iamprasertkun, N. Chanlek, C. Shepherd, E. Hadzifejzovic, M. G. Moloney, J. S. Foord and M. Sawangphruk, Electrochimica. Acta, 2017, 238, 64-73.

22 G. Ma, Z. Zhang, H. Peng, K. Sun, F. Ran and Z. Lei, J. Solid State Electrochem., 2016, 20, 1613-1623.

23 Q. Liu, J. Zhong, Z. Sun and H. Mi, Appl. Surf. Sci., 2017, 396, 1326-1334.

24 B. Chang, H. Yin, X. Zhang, S. Zhang and B. Yang, Chem. Eng. J., 2017, 312, 191-203.

25 X. Yang, C. Li and R. Fu, J. Power Sources, 2016, 319, 66-72. 26 J. Ludwinowicz and M. Jaroniec, Carbon, 2015, 94, 673-679. 27 Q. Shi, R. Zhang, Y. Lv, Y. Deng, A. A. Elzatahrya and D. Zhao, Carbon, 2015, 84, 335-346.

28 W. Kim, M. Y. Kang, J. B. Joo, N. D. Kim, I. K. Song, P. Kim, J. R. Yoon and J. Yi, J. Power Sources, 2010, 195, 2125-2129.

29 Z. Y. Sui, Y. N. Meng, P. W. Xiao, Z. Q. Zhao, Z. X. Wei and B. H. Han, ACS Appl. Mater. Interfaces, 2015, 7, 1431-1438.

30 J. Zhou, Z. Zhang, W. Xing, J. Yu, G. Han, W. Si and S. Zhuo, Electrochimica. Acta, 2015, 153, 68-75.

31 Y. Zhao, M. Liu, X. Deng, L. Miao, P. K. Tripathi, X. Ma, D. Zhu, Z. Xu, Z. Hao and L. Gan, Electrochimica. Acta, 2015, 153, 448-455.

32 G. Sun, B. Li, J. Ran, X. Shen and H. Tong, Electrochimica. Acta, 2015, 171, 13-22.

33 P. Hao, Z. Zhao, Y. Leng, J. Tian, Y. Sang, R. I. Boughton, C. P. Wong, H. Lin and B. Yang, Nano Energy, 2015, 15, 9-23.

34 S. Anandhavelu, V. Dhanasekaran, V. Sethuraman and H. J. Park, J. Nanosci. Nanotechnol., 2016, 16, 1-8.

35 Z. Ling, C. Yu, X. Fan, S. Liu, J. Yang, M. Zhang, G. Wang, N. Xiao and J. Qiu, Nanotechnology, 2015, 26, 374003.

36 K. Lota, I. Acznik, A. Sierczynska and G. Lota, Mater. Lett., 2016, 173, 72-75.

37 Y. Zhang, J. Y. Zhu, H. B. Ren, Y. T. Bi and L. Zhang, Chin. Chem. Lett., 2017, 28, 935-942.

38 Z. Ling, G. Wang, M. Zhang, X. Fan, C. Yu, J. Yang, N. Xiao and J. Qiu, Nanoscale, 2015, 7, 5120-5125.

39 A. Śliwak, N. Díez, E. Miniach and G. Gryglewicz, J. Appl. Electrochem., 2016, 46, 667-677.

40 L. Zhu, F. Shen, R. L. Smith and X. Qi, Energy Technol., 2016, 4, 1-10.

41 E. Lih, J. S. Lee, K. M. Park and K. D. Park, Acta Biomater., 2012, 8, 3261-3269. 
42 F. Ganji and M. J. Abdekhodaie, Carbohydr. Polym., 2008, 74, 44 F. Gao, J. Qu, Z. Zhao, Z. Wang and J. Qiu, Electrochimica. 435-441. Acta, 2016, 190, 1134-1141.

43 A. Altinisik and K. Yurdakoc, J. Appl. Polym. Sci., 2011, 122, 45 L. B. Xing, J. L. Zhang, J. Zhang, S. F. Hou, J. Zhou, W. Si, 1556-1563. H. Cui and S. Zhuo, Electrochim. Acta, 2015, 176, 1288-1295. 